George F. Livingston - Stacy M. Philpott

\title{
A metacommmunity approach to co-occurrence patterns and the core-satellite hypothesis in a community of tropical arboreal ants
}

Received: 6 April 2010/ Accepted: 31 May 2010/Published online: 15 July 2010

(C) The Ecological Society of Japan 2010

\begin{abstract}
Inferring mechanisms of community assembly from co-occurrence patterns is difficult in systems where assembly processes occur at multiple spatial scales and among species with heterogeneous dispersal abilities. Here, we demonstrate that local scale analysis of co-occurrence patterns is inadequate to fully describe assembly mechanisms and instead utilize a metacommunity and core-satellite approach. We generated a co-occurrence and life-history data set for a community of twig-nesting ants on coffee plants across 36 sites within a tropical agroecosystem to test the following three hypotheses: (1) twig-nesting ant species compete for nest-sites, (2) they are structured as a metacommunity, and (3) core species show segregated patterns, while satellite species show random patterns of co-occurrence. Species were divided into four groups: core species that are well distributed regionally and dominant locally, regional dominants that are well distributed regionally but do not dominate locally, local dominants that are dominant locally but are not widely distributed, and satellites that are neither widely distributed nor dominant locally. Only the most abundant species in the community, Pseudomyrmex simplex, was classified as a core species. Regional dominants, local dominants, and satellite species show random patterns of co-occurrence. However, when P. simplex is
\end{abstract}

G. F. Livingston

Department of Ecology and Evolutionary Biology, University of Michigan, 430 N. University,

Ann Arbor, MI 48109, USA

S. M. Philpott

Department of Environmental Sciences,

University of Toledo, $2801 \mathrm{~W}$ Bancroft St.,

Mail Stop \#604, Toledo, OH 43606, USA

Present address: G. F. Livingston $(\bowtie)$

Section of Integrative Biology,

University of Texas at Austin,

1 University Station C0930, Austin, TX 78712, USA

E-mail: gliv@mail.utexas.edu

Tel.: + 1-208-7211145 included in the co-occurrence matrix, patterns become aggregated for all three species groupings. This suggests that $P$. simplex "assembles" the community by providing a core metapopulation that other species track. Analyzing co-occurrence patterns among candidate subsets of species, at multiple spatial scales, and linking them to species traits substantially improves the explanatory power of co-occurrence analyses in complex metacommunities.

Keywords Assembly · Core-satellite hypothesis .

Metacommunity $\cdot$ Tropical ecology $\cdot$ Co-occurrence

\section{Introduction}

Species co-occurrence patterns have been used to infer a range of mechanisms assembling ecological communities. These mechanisms include interspecific competition (Diamond 1975), habitat filtering (Horner-Devine et al. 2007), body size and energy constraints (Gotelli and McCabe 2002), phylogenetic and historical influences (Cavender-Bares et al. 2006), and neutral processes (Kelly et al. 2008), among others. Dispersal plays an implicit role in driving many of these mechanisms. Habitat filtering, for example, requires that species are able to disperse to suitable environments. However, a general framework incorporating dispersal is lacking. The presence and magnitude of dispersal of interacting species among local communities (forming a metacommunity, i.e., Leibold et al. 2004) should influence co-occurrence patterns given the diverse ways in which dispersal can impact species coexistence (Amarasekare et al. 2004). Leibold and Mikkelson (2002) identified a number of metrics to describe co-occurrence patterns within metacommunities, but these are largely independent of assembly processes. Utilizing co-occurrence data is important given that relative species abundance distributions are of limited use in distinguishing among mechanisms (Adler et al. 2007). 
Many metacommunities are composed of species with heterogeneous dispersal abilities and that differ in niche breadth (Pandit et al. 2009). One way to address dispersal heterogeneity is to identify "core" and "satellite" species (Hanski 1982). Core species are dominant in communities and are common at both local and regional scales, whereas satellite species are rare both locally and regionally. The "core-satellite" distinction can either form ends of a continuum or distinct clusters of species depending on the assemblage considered (Hanski and Gyllenberg 1993). Interspecific competition among core species should result in nonrandom segregated patterns of co-occurrence (Ulrich and Zalewski 2006). In contrast, satellite species should show random or aggregated co-occurrence patterns resulting from the effects of dispersal (Ulrich and Zalewski 2006) or habitat segregation (Pandit et al. 2009).

Several hypotheses have been proposed to explain the occurrence of core and satellite species. These include incomplete sampling (Selmi and Boulinier 2004) and biological mechanisms such as the distribution of heterogeneous habitats, dispersal ability, relative geometry of geographic ranges, and metapopulation dynamics (McGeoch and Gaston 2002). However, few empirical tests have distinguished among mechanisms driving core-satellite patterns (but see Holt et al. 2002). Co-occurrence analyses provide one way to test among possible mechanisms (Ulrich and Zalewski 2006). Studies further linking clusters of core and satellite species to relevant life history traits (e.g., dispersal ability) are needed (Cadotte and Lovett-Doust 2007).

In this study we focus on an arboreal community of neotropical twig-nesting ants that opportunistically utilize dry hollow twigs (Carroll 1979) on coffee plants within a tropical agroecosystem. Coffee plants act as uniformly distributed patches between which ants migrate via the dispersal of queens and direct movement of nests. Coffee is a relatively homogeneous environment, with plants differing in a limited number of characteristics, including the size and number of nestsites available (effectively setting local carrying capacity), plant height, identity of nearby species of shade trees, and the extent of disturbance by an aggressive carton nesting species, Azteca instabilis (Philpott 2010). Importantly, previous research has demonstrated that this community is nest-site limited (Philpott and Foster 2005). Research focusing on $A$. instabilis, other arboreal ants in the shade tree canopy, hemipteran assemblages, predatory beetles, and fungal pathogens has demonstrated the capacity of coffee agroecosystems to elucidate mechanisms driving intrinsic pattern formation (e.g., Philpott 2006; Liere and Perfecto 2008; Livingston et al. 2008; Vandermeer et al. 2008). Thus, abundanceoccupancy patterns can be interpreted against a background of manageable complexity.

We utilized a combination of survey, experimental, and simulation data to explore how co-occurrence patterns may result from metacommunity dynamics and how those patterns differ between core and satellite species. Specifically, we tested the following three hypotheses: (1) species compete for nest-sites, (2) they exist in local communities linked by dispersal (i.e., the twig-nesting ant community is a metacommunity), and (3) core species show segregated co-occurrence patterns due to the effects of interspecific competition, while satellite species show random or aggregated patterns resulting from stochastic dispersal. Taken together, hypotheses one and two test for a competitive metacommunity structure. We tested hypothesis one by measuring natural nests to determine if species use similar nest-sites or if local scale microhabitat partitioning precludes direct interaction. We also experimentally tested for nest-site preferences to confirm the role of competition in generating field patterns. We tested hypotheses two and three by dividing the community into four classes of core and satellite species based on clustering within an abundance-occupancy distribution and with respect to life-history traits. We then ran co-occurrence simulations for each of these species groups. Finally, to determine the relative influence of competition and stochastic dispersal on co-occurrence patterns we constructed a behavioral dominance hierarchy and correlated the metacommunity abundance of each species with local community properties.

\section{Methods}

We conducted this study during June and July of 2007 in a 45-ha plot within Finca Irlanda, a 300-ha traditional organic shaded coffee agroecosystem in the Soconusco region of Chiapas, Mexico $\left(15^{\circ} 10^{\prime} \mathrm{N}\right.$ and $92^{\circ} 20^{\prime} \mathrm{W}$, $950 \mathrm{~m}$ elevation, $\sim 4,500 \mathrm{~mm}$ rain annually). The agroecosystem is comprised of a shade canopy and an understory of coffee plants. The canopy in Finca Irlanda is diverse (>200 species) but dominated by Inga micheliana and Alchornea latifolia (Perfecto and Vandermeer 2002). The farm is managed as a commercial polyculture (Moguel and Toledo 1999).

We used thirty-six randomly selected sites from across the plot (extending from a focal shade tree) to survey the twig-nesting ant community. To control for possible effects of tree species we established half of the sites beneath I. micheliana, and the other half beneath A. latifolia trees. To assess the impact of disturbance on the community, half of these sites contained nests of $A$. instabilis (at least 2 years old), while the remaining half did not and were instead situated at least $20 \mathrm{~m}$ from $A$. instabilis nests. Sites were $1.5 \times 10 \mathrm{~m}$ transects extending from the base of a shade tree. In addition to random tree selection, the direction of each transect was chosen at random among the eight cardinal and intercardinal directions. All coffee plants with a basal stalk within the transect were included. Transects contained between 9 and 23 plants.

At each plant, we snapped off and opened all dry twigs and noted the total number of dry twigs, hollow twigs, and twigs occupied by ants. We included as nests 
twigs containing any number of workers, pupa/larvae, and/or reproductive individuals (Philpott and Foster 2005) and for each nest encountered, we counted the number of individuals and alates (winged individuals). All nests of each species on a plant were assumed to constitute a single colony (Frederickson 2006; Yu et al. 2001). Polydomy, but not polygyny, has been reported for some species in this community (DeBout et al. 2007). We collected ants and identified them using a photographic guide to the ants of the region (Philpott, unpublished) and published guides for neotropical ants (Fernández 2003; Longino 2007). We quantified A. instabilis activity by scanning each plant for ants then using a standardized procedure to record ant activity by counting the number of individuals that crossed a reference point within 1 min (Livingston et al. 2008). At some sites, we measured plant height. Finally, for up to 20 unopened nests of each species, we measured the long and short (cavities were oval) width of both the hollow and total ellipse of the twig at the centermost cutaway of the hollow portion. These values were used to calculate the area of the hollow cavity ellipse using the area equation for an ellipse.

To test for nest-site competition (hypothesis one) we first used ANOVA to examine whether species occupied different sized nests in the field. This allowed us to infer the level of microhabitat partitioning among species. Since nest-sites are limiting in this system (Philpott and Foster 2005) and nest-site takeovers are common in ants (Palmer et al. 2002), we assumed that this resource axis drives competitive interactions if they occur. However, microhabitat partitioning alone cannot confirm the presence or absence of competition because species may have habitat preferences outside of microhabitats they are observed to occupy in the field. Thus, we experimentally tested for species preferences for particular nest sizes using laboratory trials with artificial hollow twigs (bamboo open at one end). We selected two species for this analysis: $P$. hylaeus because field data indicated it uses a larger nest-site than other species and Pseudomyrmex simplex as the most abundant species using smaller hollow twigs.

We used artificial twigs with hollow diameters between 1.5 and $2.5 \mathrm{~mm}$, to mirror the natural nest-size distribution (except for Procryptocerus hylaeus, see below). We provided sugar, protein (tuna), ventilation, and moisture to sustain nests. We broke apart natural nests and placed them into plastic containers. We then gave ants $24 \mathrm{~h}$ to colonize an artificial twig. Following the initial colonization, we placed each colony into a container with a small (1.5-2.5 mm cavity diameter) and a large (2.6-4.0 $\mathrm{mm}$ ) bamboo. After $24 \mathrm{~h}$, we opened both twigs and recorded the size selected. Twelve of these trials were conducted with $P$. simplex and 20 with P. hylaeus. A chisquared test was used to analyze nest preferences. For these tests and all subsequent statistical tests, count data were normally distributed or normal after log transformation. QQ plots were used to infer normality and box plots were created to test assumptions of equal population variance. All statistical tests were conducted using SPSS v. 17.

In our co-occurrence analyses, we wanted to ensure that observed co-occurrence patterns resulted from competition among ant species and stochastic dispersal rather than through shared habitat preferences. To do this, we assessed whether species and community level responses to environmental gradients were linear and equivalent among species. We considered the two critical environmental gradients as nest-site abundance and disturbance by $A$. instabilis. We used linear regressions to correlate the number of hollow twigs per plant with colony size and species richness (established colonies). We also conducted an identical regression for species richness at the site scale by summing plant totals. We used an ANCOVA test for homogeneity of regressions (VassarStats 2010) to test whether species showed similar responses (with respect to colony size and the proportion of the community occupied) to increasing numbers of hollow twigs on coffee. We used EstimateS v8.0 (Colwell 2005) to estimate total species richness, compare richness and similarity between sites with and without $A$. instabilis, and to assess whether the survey captured an appropriate sample size. We used 95\% confidence intervals for all estimates of species richness and community similarity.

The third hypothesis we tested was that core species show segregated co-occurrence whereas satellite species are random or aggregated. This involved (1) identifying core and satellite species, (2) testing co-occurrence patterns within each of these groups separately, and (3) identifying possible mechanisms generating these patterns. We correlated the mean local relative abundance (proportion of total twigs occupied per transect) of species at each of the 36 sites with the total number of sites where each species occurred (regional distribution) to generate an abundance-occupancy regression. We used a K-means analysis to identify clusters of species falling into the following four categories: abundant regionally and locally (core species), abundant regionally only (regional dominants), abundant locally only (local dominants), and rare both locally and regionally (satellites). Following natural breakpoints in the data and the clustering analysis, we considered species to be local dominants if their mean local relative abundance was greater than $40 \%$ and regional dominants if they occupied more than 10 of the 36 sites. To test if these clusters are biologically relevant, we compared mean colony sizes, alate production, behavioral dominance, and levels of interspecific co-occurrence among these groups using ANOVA.

To test for patterns of species co-occurrence we used EcoSim v. 8 (Gotelli and Entsminger 2007). Co-occurrence simulations were conducted for all species encountered and then for each species category separately. Additionally, we ran simulations for all species and for each species category with and without presence/absence data for the one core species for a total of eight simulations each at the coffee plant and site scale. We used the "species co-occurrence" 
function to generate a variance ratio (V ratio) statistic for each simulation. The $\mathrm{V}$ ratio measures the amount of variation in species richness when accounting for species metacommunity abundances and the differential sizes of sites (Gotelli 2000). A V ratio greater than, less than, or equal to one indicates that species covary positively, negatively, or do not covary with each other, respectively, in a presence/absence matrix (Schluter 1984). For each simulation, we used proportional settings for both column and row totals. This means single plants or sites with more species are more likely to receive a new species and more abundant species have higher arrival probabilities. Each simulation included 1,000 iterations (Gotelli and Entsminger 2007).

We then wanted to determine if stochastic dispersal or competition better explained the observed cooccurrence patterns for each species grouping. To probe the role of dispersal, we correlated metacommunity abundance of each species with dispersal and colonization ability, maximum colony size, and empirical ratios of co-occurrence frequency. These correlations also represent a test of metacommunity structuring by assessing the impact of a regional property (metacommunity abundance) on local community structure. Dispersal was measured as the total number of de-alate lone queens found (observed dispersal), colonization ability is the number of times a species occupied plants with only one available nestsite (apparent colonization ability), and maximum colony size is the maximum number of nests observed on a single coffee plant. Alate production among neotropical ants peaks during the wet season (the time of our study) and appears to be less seasonal in some twig-nesting genera (Kaspari et al. 2001). Our dispersal data are therefore unlikely to be confounded with alate phenology.

To test for asymmetric (non-neutral) competition, we tested for a dominance hierarchy. We fought pairs of species in the lab using the same set up described for nest preference trials. We discarded the original twigs and placed colonies (including larvae/pupa) of two species in a plastic container with a single new artificial twig. We then gave ants $24 \mathrm{~h}$ to colonize the bamboo. We considered the species that placed all its pupa/ larvae and most of its workers in the bamboo after $24 \mathrm{~h}$ dominant for that trial. If neither species occupied the bamboo, the ants were given another $24 \mathrm{~h}$. If after $48 \mathrm{~h}$ no occupation or co-occupation occurred, we discarded the trial. We fought species haphazardly by pairing species as nests became available from field surveys until five trials with each pair were completed. If the outcome of all trials involving two particular species was indecisive, we placed species in the same dominance rank. Rare species that could not be fought at least five times were not ranked. Especially large or small nests of each species were paired together, but natural asymmetries in colony size were maintained. We used ant colonies twice $(N=5)$ only if they suffered no mortality or desiccation during trials. Overall,

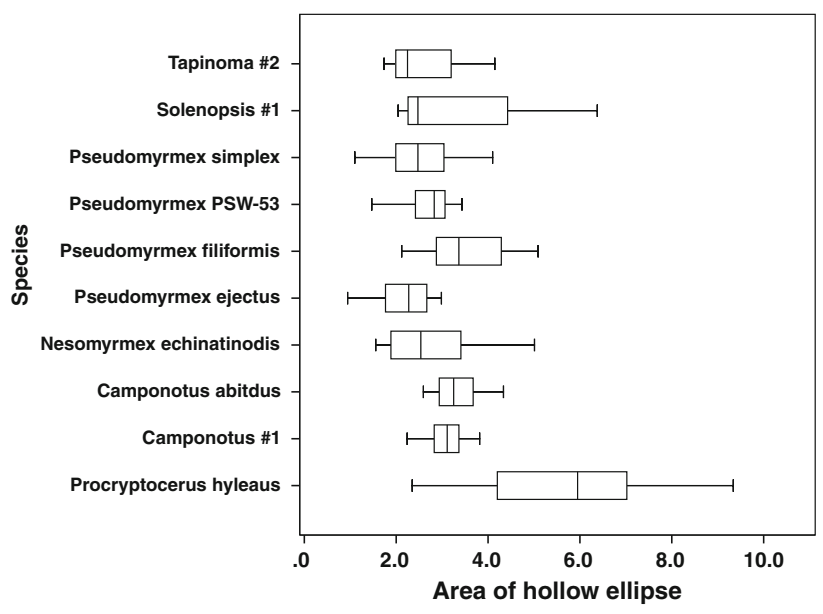

Fig. 1 Box and whisker plot of the distribution of the area $\left(\mathrm{mm}^{2}\right)$ of the hollow portion of twigs for species with at least three nests measured. P. hylaeus (bottom) utilized significantly larger nest-sites (Tukey's procedure, $P<0.05$ for each species), while other species showed nonsignificant variation

we ran 76 trials, of which five were discarded. We evaluated results using a chi-squared test.

\section{Results}

We surveyed a total of 9,784 dry twigs from 520 coffee plants. We recorded 25 ant species among 9,687 individuals, 719 nests, and 377 colonies. Measurement of twig dimensions revealed that $P$. hylaeus $(N=95)$ utilized twigs with a larger elliptical area than other species (Fig. 1). All other species used similar sized nests in the field. In laboratory preference trials, $P$. simplex occupied 11 small and 1 large twig, whereas $P$. hylaeus occupied 3 small and 17 large twigs. This demonstrated that $P$. hylaeus prefers larger $(2.6-4.0 \mathrm{~mm})$ artificial twigs relative to $P$. simplex $(d f=1, P<0.01)$. Given that $P$. hylaeus also shows no correlation with the abundance or composition of other ants in the system (Livingston and Philpott, unpublished data), we did not include this species in other analyses.

The community included many rare species, with nine species represented by only one or two colonies. The two most abundant species, P. simplex and Nesomyrmex echinatinodis, represented 40 and $16 \%$ of all colonies found, respectively. Data on number of colonies, established colonies (queen plus at least one worker), number of lone queens, sites present, proportion of alate individuals, and mean colony size for each species are summarized in Table 1. Total estimated species richness (Chao 2) was 22.19 species (SD -1.05, +9.13), compared with 22 observed species. The number of hollow twigs present on individual plants ranged from 1 to 46, but $50 \%$ of plants contained only 1 or 2 hollow twigs. The percentage of twigs occupied by ants did not differ significantly with the number of hollow twigs on each plant $(P=0.14)$. On average, $65 \%$ of hollow twigs on each plant were occupied, but this likely underestimates 
Table 1 Distribution, abundance, and life history data by species

\begin{tabular}{|c|c|c|c|c|c|c|c|c|c|c|c|c|c|c|}
\hline Species & Type & $N$ total & $\begin{array}{l}N \\
\text { queens }\end{array}$ & $\begin{array}{l}N \\
\text { established }\end{array}$ & $\begin{array}{l}\text { No. of sites } \\
\text { dispersed }\end{array}$ & $\begin{array}{l}\text { No. of sites } \\
\text { recruited }\end{array}$ & $\begin{array}{l}\text { Mean relative } \\
\text { local established } \\
\text { abundance }\end{array}$ & $\begin{array}{l}\text { Co-occur/ } \\
N \text { total }\end{array}$ & $\begin{array}{l}N \text { first } \\
\text { colonists }\end{array}$ & $\begin{array}{l}\ln \text { win/ } \\
\text { loss ratio }\end{array}$ & $\begin{array}{l}\text { Mean } \\
\text { no. of } \\
\text { nests }\end{array}$ & $\begin{array}{l}\text { Max } \\
\text { no. of } \\
\text { nests }\end{array}$ & $\begin{array}{l}\text { Mean } \\
\text { no. of } \\
\text { individuals }\end{array}$ & $\begin{array}{l}\text { Mean } \\
\text { proportion } \\
\text { of alates }\end{array}$ \\
\hline Pseudomyrmex simplex (4) & $\mathrm{C}$ & 103 & 27 & 76 & 32 & 26 & 0.52 & 0.351 & 48 & -0.798 & 2.202 & 8 & 29.229 & 0.077 \\
\hline Nesomyrmex echinatinodis (3) & $\mathrm{RD}$ & 40 & 1 & 39 & 17 & 17 & 0.28 & 0.565 & 13 & 1.386 & 1.538 & 6 & 35.410 & 0.053 \\
\hline Pseudomyrmex ejectus (4) & $\mathrm{RD}$ & 26 & 8 & 18 & 16 & 13 & 0.16 & 0.633 & 7 & -0.6931 & 1.666 & 3 & 18.5 & 0.056 \\
\hline Camponotus abitdus (3) & LD & 17 & 3 & 14 & 8 & 6 & 0.43 & 0.695 & 4 & 0.980 & 2.357 & 6 & 57.285 & 0.026 \\
\hline Pseudomyrmex PSW-53 (1) & LD & 9 & 3 & 6 & 5 & 4 & 0.49 & 0.916 & 1 & 0.810 & 4.4 & 8 & 37.555 & 0.154 \\
\hline Pseudomyrmex filiformis (2) & LD & 5 & 1 & 4 & 5 & 4 & 0.49 & 0.428 & 2 & 0.9162 & 17.4 & 1 & 129.25 & 0.015 \\
\hline Myrmelachista mexicana & LD & 4 & 0 & 4 & 2 & 2 & 0.62 & 0 & 1 & 0 & 3.75 & 5 & 117.25 & 0.714 \\
\hline Camponotus \#1 (3*) & $\mathrm{S}$ & 12 & 2 & 10 & 8 & 6 & 0.18 & 0.764 & 5 & 0.510 & 1.777 & 3 & 25.555 & 0 \\
\hline Pseudomyrmex elongates $(4 *)$ & $\mathrm{S}$ & 7 & 4 & 3 & 7 & 3 & 0.22 & 0.875 & 1 & -1.609 & 2 & 2 & 9.666 & 0.008 \\
\hline Dolichoderus lutosus & $\mathrm{S}$ & 6 & 4 & 2 & 3 & 1 & 0.13 & 0.909 & 1 & -0.693 & 2 & 3 & 7.5 & 0 \\
\hline Tapinoma \#2 & $\mathrm{S}$ & 6 & 1 & 5 & 5 & 4 & 0.3 & 0.571 & 2 & 1.098 & 1.6 & 3 & 30.4 & 0.060 \\
\hline Solenopsis \#1 & $\mathrm{S}$ & 5 & 1 & 4 & 3 & 3 & 0.1 & 0.8 & 1 & -0.916 & 1 & 1 & 55.2 & 0.012 \\
\hline Nesomyrmex pittieri & $\mathrm{S}$ & 3 & 0 & 3 & 3 & 3 & 0.14 & 0.857 & 1 & & 1 & 1 & 11 & \\
\hline Crematogaster \#2 & $\mathrm{S}$ & 2 & & 2 & 2 & 2 & 0.09 & 1 & 0 & & 1.5 & 2 & 39 & \\
\hline Crematogaster \#3 & $\mathrm{S}$ & 2 & 1 & 1 & 2 & 1 & 0.04 & 1 & 0 & 0 & 1 & 1 & 19 & 0.157 \\
\hline Crematogaster carinata & $\mathrm{S}$ & 2 & & 2 & 2 & 0 & & 0.666 & 1 & & & 1 & & \\
\hline Solenopsis \#2 & $\mathrm{S}$ & 2 & & 2 & 1 & 1 & 0.14 & 0.5 & 1 & 0 & 1 & 1 & 67.5 & 0 \\
\hline Cardiocondyla \#1 & $\mathrm{S}$ & 1 & 1 & 0 & 1 & 0 & & 1 & 0 & & & 1 & & \\
\hline Myrmelachista \#1 & $\mathrm{S}$ & 1 & 0 & 1 & 1 & 1 & 0.25 & 1 & 0 & & 1 & 1 & 14 & \\
\hline Pseudomyrmex occulatus & $\mathrm{S}$ & 1 & 1 & 0 & 1 & 0 & & 1 & 0 & & & 1 & & \\
\hline Solenopsis \#3 & $\mathrm{S}$ & 1 & & 1 & 1 & 1 & 0.04 & 1 & 0 & & 1 & 1 & 18 & 0 \\
\hline Tapinoma \#1 & $\mathrm{S}$ & 1 & & 1 & 1 & 1 & 0.03 & 1 & 0 & & 1 & 1 & 14 & \\
\hline
\end{tabular}

$N$ Number of colonies, $C$ core species, $R D$ regional dominant, $L D$ local dominant, $S$ satellite

Sites to which ants dispersed include those where queens, established colonies (queens and workers), or both were encountered of each species. Recruited sites include only those where established colonies were found. Dominance ranks are in parentheses following each species name. A starred dominance rank indicates species that were not fought against species ranked in the tier above them 


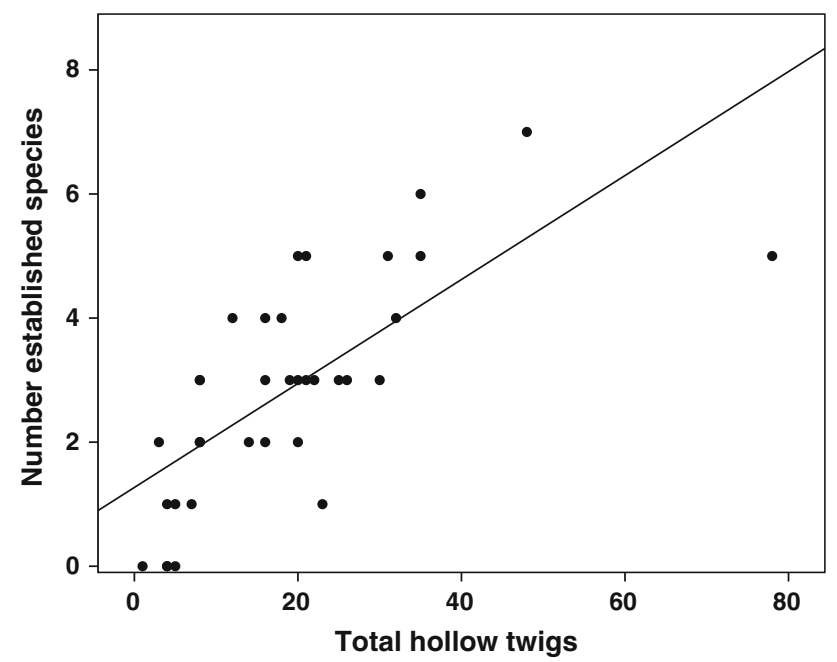

Fig. 2 Established species richness as a function of total number of hollow twigs $\left(y=1.014+0.69 x, r^{2}=0.51, P<0.0001\right)$

true occupation rates as some unoccupied twigs were wet, rotten, or of a size outside the normal limits of occupied nests (Livingston, personal observations). This relative saturation of nesting resources along a gradient of hollow twig numbers per plant allows for comparisons of both colony and community structure across that gradient.

The number of nests occupied (colony size) significantly and positively correlated with the number of hollow twigs per plant only for the most common species, $P$. simplex $\left(r^{2}=0.44, P<0.0001\right)$. For the other species, correlations between colony size and number of twigs were nonsignificant and did not correlate uniformly across species $(\mathrm{SS}=34961.32, d f=9, \quad F=4.78$, $P<0.000001)$. However, the total number of hollow twigs occupied and the proportion of those twigs each species occupied were consistently negatively correlated $(\mathrm{SS}=0.68, d f=9, F=0.78, P=0.634)$. Thus, species richness increased linearly with increasing numbers of hollow twigs at both plant $\left(r^{2}=0.27, P<0.0001\right)$ and site (Fig. 2) scales. For all species pooled, there was a strong positive relationship between the number of occupied twigs and the number of hollow twigs available at each site $\left(r^{2}=0.931, P<0.0001\right)$. Furthermore, plant height correlated with number of hollow twigs $\left(r^{2}=0.15, P<0.01\right)$. Height is correlated with age for some other species of woody perennials (Mooney and McGraw 2009).

Species richness estimates did not differ among sites with (Chao 2: 21.71, SD - 14.8, +55.18) and without A. instabilis (Chao 2: 18.48, SD -18.04, +24.07). If $A$. instabilis affected community composition, the similarity between sites with and without $A$. instabilis should be lower than the similarity within $A$. instabilis and nonA. instabilis sites. We observed the opposite pattern. According to the Chao-Sorenson abundance-based estimator there is more similarity between all sites with and all sites without $A$. instabilis $(0.965, \mathrm{SD} \pm 0.033)$
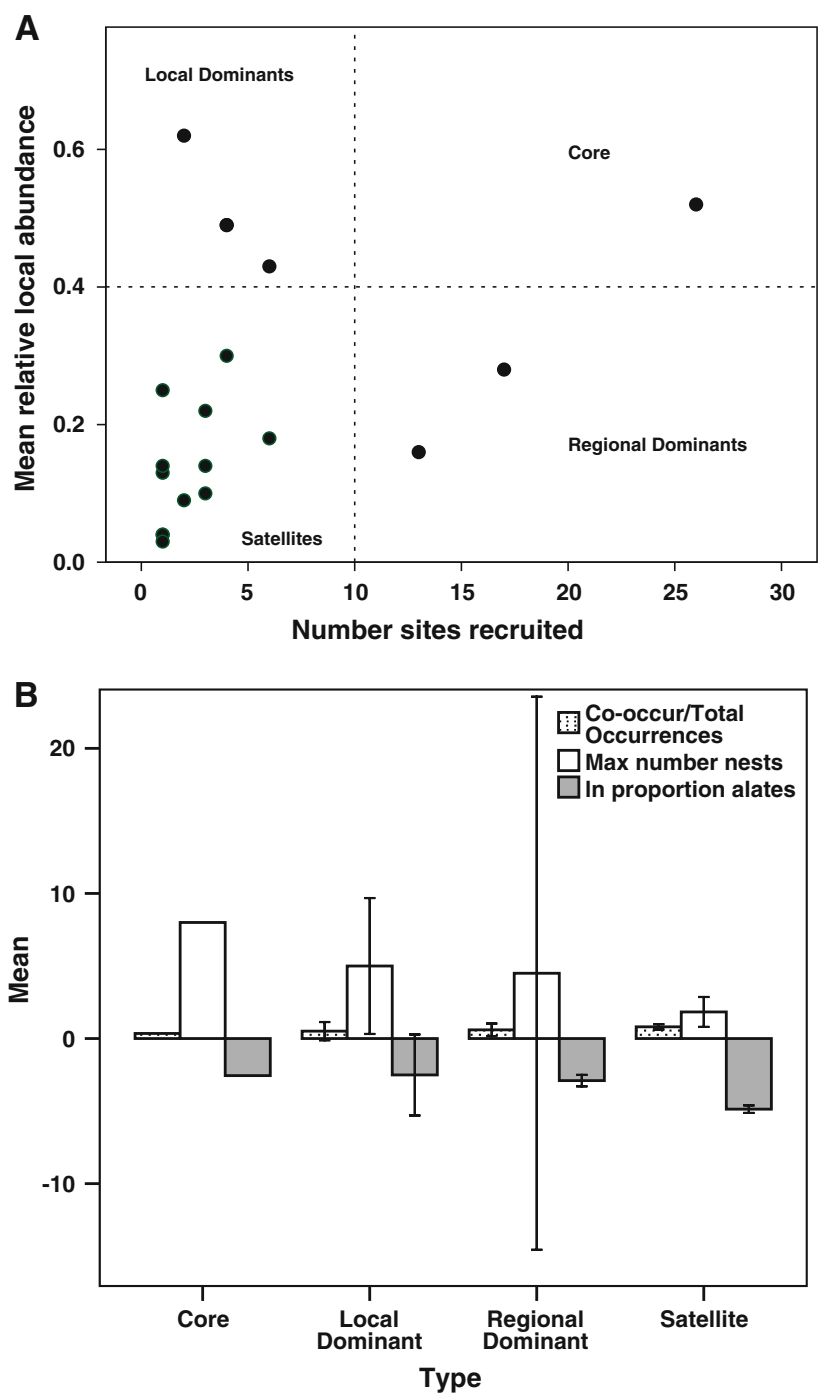

Fig. 3 a Species group clusters along the abundance-occupancy axis. Dashed lines denote the $40 \%$ mean relative local abundance and 10 sites recruited boundaries between groups. b Mean co-occurrence ratios $(F=3.052, d f=4,17, P=0.046)$, maximum colony sizes $(F=8.297, d f=4,17, P=0.001)$, and proportion of alates/colony $(F=4.87, d f=4,10, P=0.019)$ by species group. These are the only variables from Table 1 in which there was a significant effect of species grouping on mean values. Error bars represent $95 \%$ confidence intervals

than among sites with and those without this species (0.41, SD $\pm 0.23 ; 0.48, \mathrm{SD} \pm 0.25$, respectively).

A K-means clustering analysis of the abundanceoccupancy relationship separated four statistical clusters including a core species, $P$. simplex, 2 regional dominants, 5 local dominants, and 11 satellite species (ANOVA, mean squares occupancy cluster: 252.73; $d f=3 ; F=$ 180.68; $P<0.001$, mean squares abundance cluster: $0.79 ; d f=3, F=3.31 ; P<0.05$, Fig. 3a). Following site occupancy and abundance cutoffs (Fig. 3a), we moved one of the statistically identified local dominants and four unresolved species into the satellite category. These groups corresponded to significant differences in 
Table 2 Results of co-occurrence analyses for all species groups without $P$. simplex (first) followed by the analysis with $P$. simplex included (w/P. simplex)

\begin{tabular}{|c|c|c|c|c|c|c|}
\hline & $N$ & Obs $\mathrm{V}$ ratio & $\begin{array}{l}\text { Mean sim } \\
\text { V ratio }\end{array}$ & $\begin{array}{l}\text { Var V } \\
\text { ratio }\end{array}$ & $P$ value & $\begin{array}{l}\text { Co-occurrence } \\
\text { pattern }\end{array}$ \\
\hline \multicolumn{7}{|l|}{ Site scale } \\
\hline All species & 71 & 5.37475 & 4.04614 & 0.99247 & 0.0946 & Random \\
\hline $\mathrm{w} / P$. simplex & 98 & 10.39137 & 6.1213 & 1.41868 & $0.002 * *$ & Aggregated \\
\hline Regional dominants & 30 & 1.33333 & 1.35479 & 2.8215 & 0.3866 & Random \\
\hline $\mathrm{w} / P$. simplex & 57 & 7.09091 & 2.89416 & 3.65404 & 0.03* & Aggregated \\
\hline Local dominants & 15 & 0.46341 & 1.38455 & 0.88265 & 0.8402 & Random \\
\hline $\mathrm{w} / P$. simplex & 42 & 15.61429 & 9.28421 & 5.84266 & $0.0052 * *$ & Aggregated \\
\hline Satellites & 26 & 1.20661 & 1.969 & 0.53482 & 0.857 & Random \\
\hline $\mathrm{w} / P$. simplex & 53 & 13.47784 & 7.93589 & 3.03176 & $0.002 * *$ & Aggregated \\
\hline \multicolumn{7}{|l|}{ Coffee plant scale } \\
\hline All species & 119 & 12.78237 & 10.83215 & 4.41726 & 0.1726 & Random \\
\hline $\mathrm{w} / P$. simplex & 192 & 31.87784 & 26.51479 & 9.95793 & 0.0526 & Random \\
\hline Core dispersers & 56 & 8.80488 & 6.57923 & 18.23578 & 0.292 & Random \\
\hline $\mathrm{w} / P$. simplex & 129 & 20.75893 & 17.88072 & 25.82849 & 0.2716 & Random \\
\hline Core dominants & 31 & 2.73494 & 3.06757 & 3.09707 & 0.5142 & Random \\
\hline $\mathrm{w} / P$. simplex & 105 & 43.285 & 33.50519 & 25.14763 & $0.0308^{*}$ & Aggregated \\
\hline Satellites & 32 & 2.00641 & 2.68588 & 1.03587 & 0.7336 & Random \\
\hline $\mathrm{w} / P$. simplex & 105 & 48.729 & 34.4826 & 19.21154 & $0.001 * *$ & Aggregated \\
\hline
\end{tabular}

$N$ Total number of occurrences (presence/absence) of all species in each grouping, obs observed, sim simulated, var variance Note the all species category excludes $P$. simplex. Analyses are reported at the site scale and at the scale of single coffee plants $* P<0.05 ; * * P<0.01$

the means of three metacommunity scale life history attributes among groups (Fig. 3b). Generally, core, regional dominants, and local dominants had larger nests and higher alate-to-worker ratios and were more frequently alone on plants than were satellite species.

Observed communities differed in composition, with 47 unique species combinations occurring among 152 plants with ants present. Given that most species use similar sized nests and that species richness increases linearly with nest availability, our use of a $\mathrm{V}$ ratio test under proportional row and column settings is valid. Co-occurrence patterns were random for all species groups and for all species combined in the absence of $P$. simplex (Table 2; Fig. 4). For local dominants the observed $\mathrm{V}$ ratio was $<1$ at the site scale, suggesting segregation (Schluter 1984). When P. simplex presence/ absence data were included in the co-occurrence matrices, all groups at the site scale, and satellite species and local dominants at the plant scale, were aggregated. Although we restricted our colony limits to a single coffee plant, colony dynamics likely occur at scales larger than a single plant (Livingston, unpublished data). Thus co-occurrence results at the site scale more accurately reflect species population dynamics.

Dominance trials revealed a dominance hierarchy with at least four tiers. P. PSW-53 won significantly more trials when fought against $P$. filiformis, $C$. abitdus, $N$. echinatinodis, $P$. ejectus, and $P$. simplex $(P<0.05$ in all cases $)$ and was placed at the top of the hierarchy. $P$. simplex fell in the fourth tier (Table 1). For all species subjected to dominance trials, we used the natural $\log$ of the ratio of the number of wins to losses to indicate relative dominance within the community as it partially controls for different numbers of trials among species (Table 1). Dominance ranks and win/loss ratios did not relate to species groups or the life history traits measured in Table 1.

We found evidence of priority effects (Sale 1977). Of the 35 plants where two ant species of ranked dominance co-occurred, 29 hosted species of unequal rank, whereas 6 hosted species of the same rank. This pattern was not likely to have occurred by chance (chi-squared: 15.1, $d f=1, P<0.0001)$ and occurs because three of the four most common species are from different dominance ranks. No significant correlations were detected between the win/loss ratio and either the alate/worker $\left(r^{2}=0.05\right.$, $P=0.422)$ or apparent first colonist/total abundance $\left(r^{2}=0.06, P=0.435\right)$ ratios across species.

To further explore possible metacommunity dynamics driving co-occurrence, we collapsed the information in our abundance-occupancy relationship into a single metacommunity abundance value for each species (the total number of established colonies from all sites). This allowed us to eliminate our species groupings and consider species along a continuous axis that includes both abundance and occupancy information. The core species, $P$. simplex, had the highest metacommunity abundance, followed by the regional dominants, local dominants, and satellite species (Table 1). We correlated the number of established colonies with each variable in Table 1 and found significant positive correlations with (1) observed dispersal, (2) apparent colonization ability, and (3) maximum colony size (Fig. 5a-c). Further, the number of established colonies negatively correlated with interspecific co-occurrence frequency (Fig. 5d). Dispersal and recruitment limitation is also strong for most species. Fourteen species $(64 \%)$ were recorded at fewer than 5 sites and P. simplex reached only 32 sites when considering both queens and established colonies. 

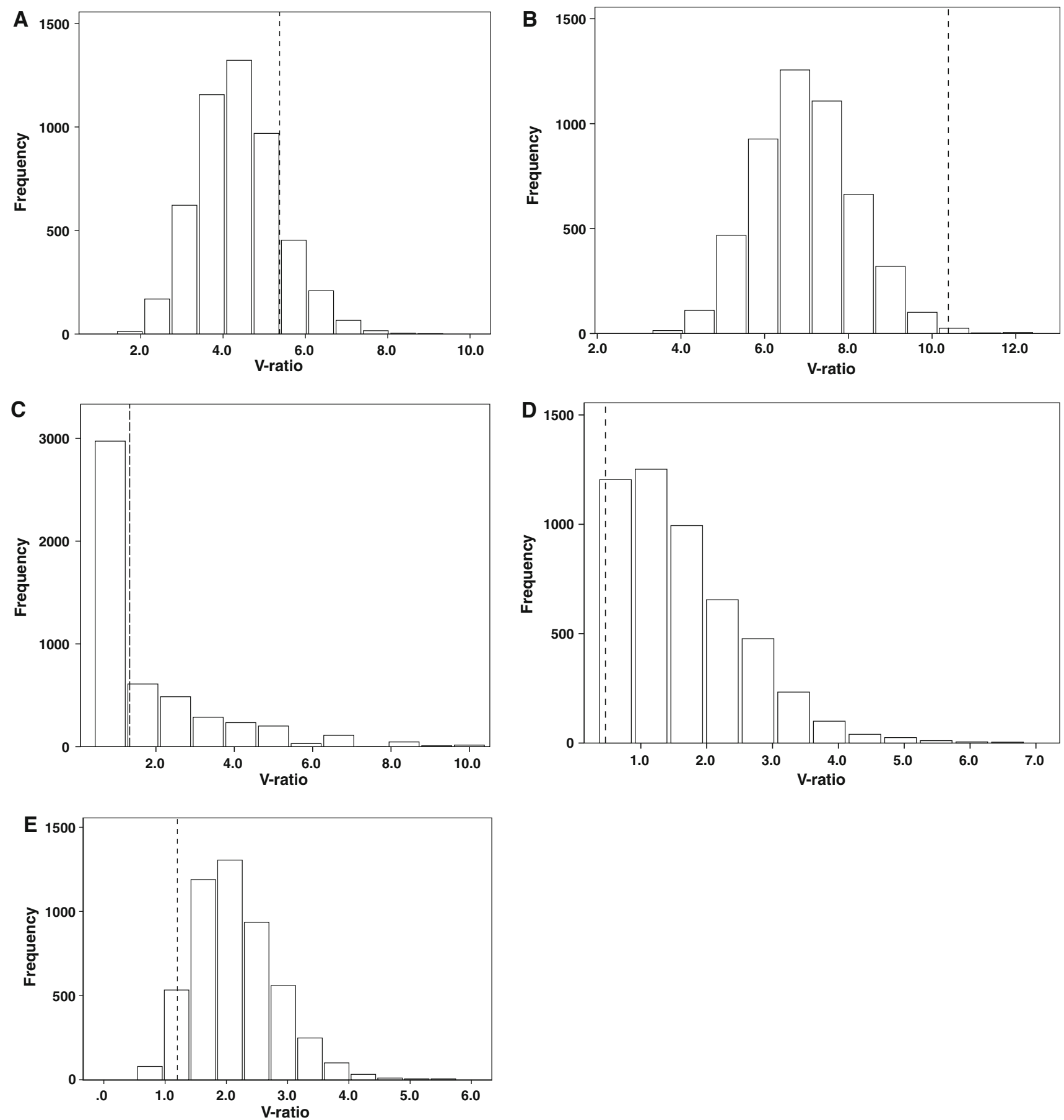

Fig. 4 Histograms of the distribution of simulated $V$ ratio scores at the site scale for a all species without $P$. simplex, $\mathbf{b}$ all species with $P$. simplex, $\mathbf{c}$ regional dominants, $\mathbf{d}$ local dominants, and e satellite species. The aggregation effect of including $P$. simplex in the $\mathbf{c}, \mathbf{d}$,

Thirteen species (59\%) dispersed to more sites than they recruited or were recorded only from queens.

\section{Discussion}

Our results support the hypothesis of competitive metacommunity structure. With the exception of

and e co-occurrence matrices is not shown because it is similar to that shown in b. Dashed lines indicate the value of the observed V ratio

P. hylaeus, all species utilize similar sized nests and show similar proportional responses to variation in nest-site availability. Nest-site limitation and the linear increase in community size with numbers of hollow twigs further suggest competition for nest-sites should be the dominant species interaction. The spatial structure, observed frequency of foundresses, and ephemeral nature of nests in this system indicates alate dispersal is likely more 

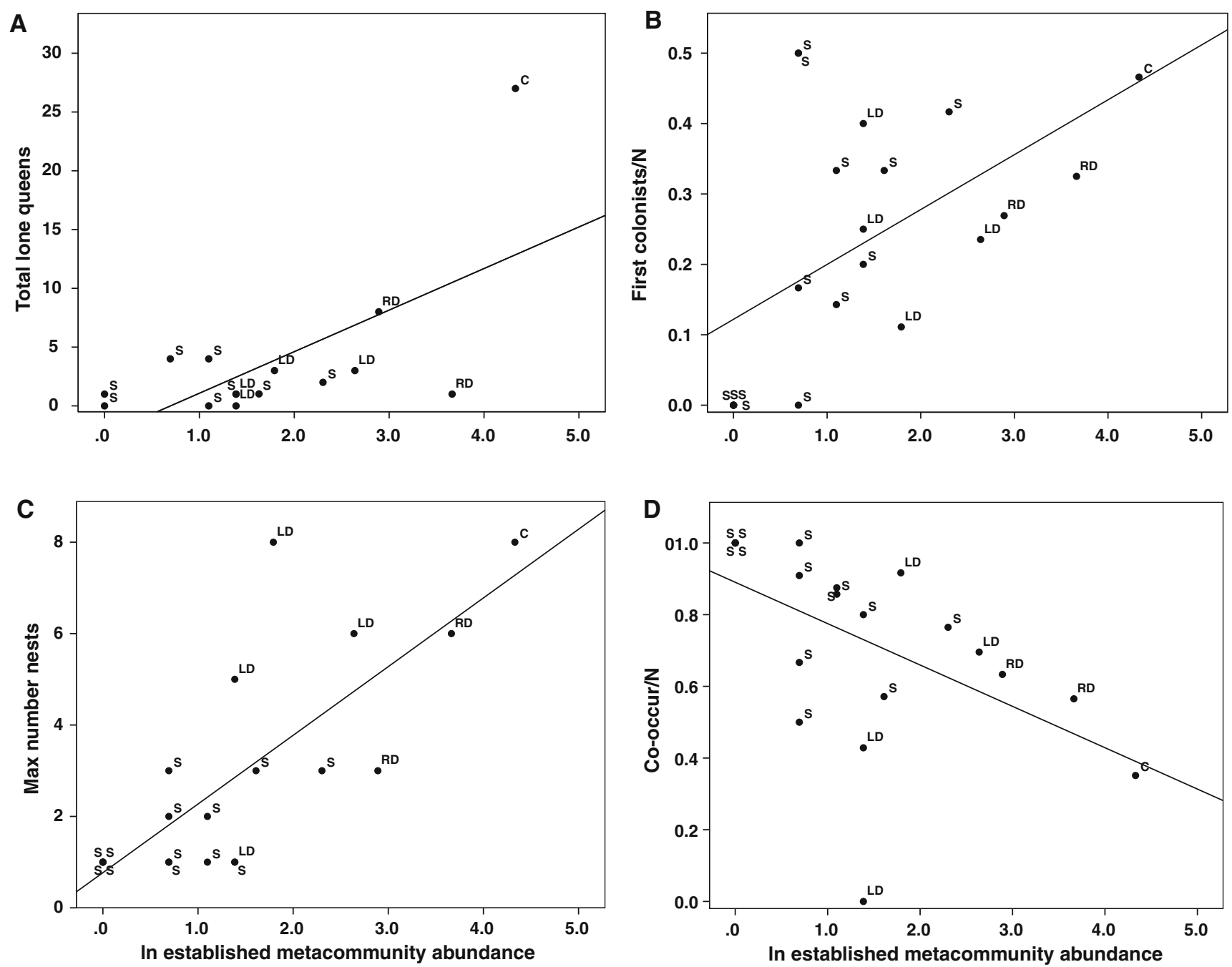

Fig. 5 Correlations between metacommunity abundance of all species and a number of lone queens $(y=-2.461+3.536 x$, $\left.r^{2}=0.41, P=0.01\right)$, b maximum number of nests $(y=0.769+$ $\left.1.503 x, r^{2}=0.59, P<0.0001\right), \quad$ c first colonist ratio $(y=$

$\left.0.122+0.078 x, r^{2}=0.29, P=0.014\right)$, and $\mathbf{d}$ co-occurrence ratio $\left(y=0.89-0.115 x, r^{2}=0.28, P=0.017\right)$. Data points are labeled by species group as in Table 1

important than colony re-localization (Byrne 1994) or super-colony dynamics (Helanterä et al. 2009) that can dominate other systems. The significant correlations between each species metacommunity abundance and local co-occurrence frequency, nest sizes, and colonization ability further suggest that feedback is occurring between metacommunity scale properties and communities on single coffee plants. Although often assumed, metacommunity structure is important to explicitly test (Holyoak et al. 2005).

Our central prediction was that core species should show segregated co-occurrence patterns, whereas satellite species should show random or aggregated patterns in a metacommunity with high homogeneity among patches. This prediction was not supported given the random patterns of co-occurrence for all groups. The low $\mathrm{V}$ ratio for the local dominants suggests segregation but should be interpreted with caution given the small sample size. However, the aggregation observed when

$P$. simplex is included in the co-occurrence matrix is a novel result. We are aware of only one published co-occurrence analysis reporting an aggregating effect of a single species on other component groups of species; aggregation of native species occurred in communities invaded by Linepithema humile in California (Sanders et al. 2003). Invasion dynamics are unlikely to have caused aggregation in our system.

Other metacommunity scale analyses have shown divergent results. Ulrich and Zalewski (2006) found segregated patterns among core species of ground beetles and random patterns among satellites. In addition, such aggregated patterns are unusual as competition is widely considered to be a key factor structuring ant communities (Hölldobler and Wilson 1990). Results from other diverse tropical agroecosystems also differ in reported co-occurrence patterns. Sanders et al. (2007) found dominant ant species "disassemble" arboreal ant communities on a cacao farm by forcing segregated 
subdominant ant assemblages to become random on trees where the dominants are present. However, in oil palm plantations normally segregated subdominant ant assemblages were aggregated when occurring with some dominant species but random with others (Pfeiffer et al. 2008). These patterns may differ from our results because the dominant versus subdominant distinction is not related to our core-satellite categories and because these studies did not use a clearly defined functionally similar guild of species.

The absence of species dominance associated with environmental conditions, the use of similar nesting resources among most species, and the lack of effect of A. instabilis on community composition [a result confirmed in Philpott (2010)] do not support a species sorting model based on abiotic environmental conditions or biotic disturbance as a driver of species aggregation. Other ground-nesting species (e.g., Solenopsis and Pheidole) are frequently found foraging and tending hemipterans on coffee, and their potential impact on the spatial distribution and abundance of twig-nesting species is unknown. However, if A. instabilis [usually dominant over other ground-nesting species (Philpott 2005)] does not impact the species composition of twignesting ants, it is unlikely that subdominant groundnesting species have strong effects. In addition, the relative homogeneity of the coffee layer reduces the likelihood that unmeasured environmental heterogeneity affects our results. $P$. simplex induces aggregation in the co-occurrence matrix because this species co-occurs with all other species and frequently in isolation (Table 1, Fig. 5d). Aggregated co-occurrence patterns may result from the metapopulation dynamics of this species. Metapopulations of larger size are more resistant to extinction (Hanski 1998). P. simplex shows limited dispersal limitation and is the most frequent first colonist among core and dominant species suggesting that its patch occupancy dynamics may be both stable and relatively independent of other species. Thus, $P$. simplex may form a "core" metapopulation tracking environmental heterogeneity (nest-site availability) and "assembling" the remainder of the community by determining which sites remain for stochastic colonization (Chase 2007). However, the aggression observed in laboratory trials and field observations of nest-site takeovers between $P$. simplex and $P$. ejectus (Livingston, personal observations) indicates that competition occurs between $P$. simplex and at least other dominants. What type of metacommunity dynamics could drive aggregated patterns in the face of competition?

Our metacommunity abundance correlations suggest $P$. simplex and local and regional dominants are better dispersers, faster colonists, and respond more strongly to nest-site resources than do satellite species. In addition, core and dominant species co-occur with other species less frequently than satellite species do (usually less than $70 \%$, Fig. 5d). P. simplex was recorded at 32 sites, whereas regional dominants were recorded at approximately half this number (16-17 sites) and local dominants at half again as many sites $(\max =8)$. Priority effects may further weaken the potential for deterministic nest-site takeovers even when competitively asymmetric species combinations are assembled.

Satellite species were recorded at few sites $(<8)$, had small colony sizes in coffee, co-occurred frequently with other species, and are likely slow colonists. Populations in the shade trees are subject to different biochemical (Armbrecht et al. 2004) and physical conditions. These populations could form a source pool from which alates "rain" into sink populations in the coffee layer. This would supplement populations of satellite species that would otherwise go extinct through competitive exclusion (Mouquet and Loreau 2002) or mainlandisland metapopulation dynamics (Ross 2006). Some satellite species, such as Dolichoderus lutosus and various Crematogaster sp. are much more abundant in tropical forest canopies (Majer and Delabie 1999; Longino 2003). Canopy surveys indicate a potential role for mass effects in this system (Livingston, unpublished data).

Our study identifies core and satellite species and links that information to co-occurrence analyses. Although we found no significant differences in co-occurrence patterns among our species groups, our life-history correlations suggest that core and satellite species fall across a gradient of relative determinism to stochasticity in metacommunity dynamics. Our results further highlight the diversity of approaches needed to interpret both co-occurrence and abundance-occupancy patterns in complex metacommunities. For example, aggregation in co-occurrence analyses is often thought to result from species with similar environmental requirements tracking a heterogeneous landscape (Gotelli and McCabe 2002). This study suggests that aggregation may also arise for other reasons such as metapopulation and metacommunity dynamics. Finally, a universal explanation for abundance-occupancy patterns may be unattainable. These patterns have been criticized as resulting purely from sampling error (Selmi and Boulinier 2004) or the frequency of suitable habitat (Storch and Šizling 2002). Here, we controlled for sampling error by utilizing a complete sampling scheme and for habitat frequency by utilizing a homogenous patch system. Under these conditions, abundanceoccupancy relationships are an underutilized but useful tool for identifying component species groups that may follow different assembly dynamics.

Acknowledgments We thank J. Vandermeer, I. Perfecto, A. De la Mora, K. Mathis, P. Bichier, G. López Bautista, and P.S. Ward for field assistance, identification of specimens, and for discussions that greatly improved this research. M. Leibold and his lab and two anonymous reviewers provided helpful comments on this manuscript. The generosity of the Peters Family allowed this work to be conducted on their farm. The University of Michigan International Institute (Individual Fellowship to G. Livingston), and Department of Ecology and Evolutionary Biology, and the National Science Foundation (Grant number DEB-0349388 to I. Perfecto and J. Vandermeer) funded this research. Voucher specimens are housed at the University of Toledo. 


\section{References}

Adler PB, Hillerislambers J, Levine JM (2007) A niche for neutrality. Ecol Lett 10:95-104

Amarasekare P, Hoopes MF, Mouquet N, Holyoak M (2004) Mechanisms of coexistence in competitive metacommunities. Am Nat 164:310-326

Armbrecht I, Perfecto I, Vandermeer J (2004) Enigmatic biodiversity correlations: ant diversity responds to diverse resources. Science 304:284-286

Byrne MM (1994) Ecology of twig-dwelling ants in a wet lowland tropical forest. Biotropica 26:61-72

Cadotte MW, Lovett-Doust J (2007) Core and satellite species in degraded habitats: an analysis using Malagasy tree communities. Biodivers Conserv 16:2515-2529

Carroll CR (1979) A comparative study of two ant faunas: the stem-nesting ant communities of Liberia, West Africa and Costa Rica, Central America. Am Nat 113:551-561

Cavender-Bares J, Keen A, Miles B (2006) Phylogenetic structure of Floridian plant communities depends on spatial and taxonomic scale. Ecology 87:109-122

Chase JM (2007) Drought mediates the importance of stochastic community assembly. Proc Nat Acad Sci USA 104:17430-17434

Colwell RK (2005) EstimateS: Statistical estimation of species richness and shared species from samples, v. 8.0. User's guide and application. http://purl.oclc.org/estimates

Debout G, Schatz B, Elias M, McKey D (2007) Polydomy in ants: what we know, what we think we know, and what remains to be done. Biol J Linn Soc 90:319-348

Diamond JM (1975) Assembly of species communities. In: Cody ML, Diamond JM (eds) Ecology and evolution of communities. Harvard University Press, Cambridge, pp 342-444

Fernández F (2003) Introducción a las hormigas de la región neotropical. Instituto de Investigación de Recursos biológicos Alexander von Humboldt, Bogotá, Colombia

Frederickson ME (2006) The reproductive phenology of an Amazonian ant species reflects the seasonal availability of its nest sites. Oecologia 149:418-427

Gotelli NJ (2000) Null model analysis of species co-occurrence patterns. Ecology 81:2606-2621

Gotelli NJ, Entsminger GL (2007) EcoSim: null models software for ecology, v. 7. http://garyentsminger.com/ecosim.htm

Gotelli NJ, McCabe DJ (2002) Species co-occurrence: a metaanalysis of J. M. Diamond's assembly rules model. Ecology 83:2091-2096

Hanski I (1982) Dynamics of regional distribution: the coresatellite species hypothesis. Oikos 38:210-221

Hanski I (1998) Metapopulation dynamics. Nature 396:41-49

Hanski I, Gyllenberg M (1993) Two general metapopulation models and the core-satellite species hypothesis. Am Nat 142:17-41

Helanterä H, Strassmann JE, Carrillo J, Queller DC (2009) Unicolonial ants: where do they come from, what are they and where are they going? Trends Ecol Evol 24:341-349

Hölldobler B, Wilson EO (1990) The ants. Springer, Berlin

Holt AR, Warren PH, Gaston KJ (2002) The importance of biotic interactions in abundance-occupancy relationships. J Anim Ecol 71:846-854

Holyoak M, Leibold MA, Mouquet N, Holt RD, Hoopes MF (2005) Metacommunities: a framework for large-scale community ecology. In: Holyoak M, Leibold MA, Holt RD (eds) Metacommunities: spatial dynamics and ecological communities. University of Chicago Press, Chicago, pp 1-32

Horner-Devine MC, Silver JM, Leibold MA, Bohannan BJM, Colwell RK, Fuhrman JA, Green JL et al (2007) A comparison of taxon co-occurrence patterns for macro- and microorganisms. Ecology 88:1345-1353

Kaspari M, Pickering J, Longino J, Windsor D (2001) The phenology of a Neotropical ant assemblage: evidence for continuous and overlapping reproduction. Behav Ecol Sociobiol 50:382-390
Kelly CK, Bowler MG, Pybus O, Harvey PH (2008) Phylogeny, niches and relative abundance in natural communities. Ecology 84:962-970

Leibold MA, Mikkelson GM (2002) Coherence, species turnover, and boundary clumping: elements of meta-community structure. Oikos 97:237-250

Leibold MA, Holyoak M, Mouquet N, Amarasekare P, Chase JM, Hoopes MF et al (2004) The metacommunity concept: a framework for multi-scale community ecology. Ecol Lett 7:601-613

Liere H, Perfecto I (2008) Cheating on a mutualism: indirect benefits of ant attendance to a coccidophagous coccinellid. Environ Entomol 37:143-149

Livingston GF, White AM, Kratz CJ (2008) Indirect interactions between ant-tended hemipterans, a dominant ant Azteca instabilis (Hymenoptera: Formicidae), and shade trees in a tropical agroecosystem. Environ Entomol 37:734-740

Longino JT (2003) The Crematogaster (Hymenoptera, Formicidae, Myrmicinae) of Costa Rica. Zootaxa 151:1-150

Longino JT (2007) Ants of Costa Rica. http://academic.evergreen. edu/projects/ants/AntsofCostaRica.html

Majer JD, Delabie JHC (1999) Impact of tree isolation on arboreal and ground ant communities in cleared pasture in the Atlantic rain forest region of Bahia, Brazil. Insect Soc 46:281-290

McGeoch MA, Gaston KJ (2002) Occupancy frequency distributions: patterns, artefacts and mechanisms. Biol Rev 77:311-331

Moguel P, Toledo VM (1999) Biodiversity conservation in traditional coffee systems of Mexico. Conserv Biol 13:11-21

Mooney EH, McGraw JB (2009) Relationship between age, size, and reproduction in populations of American ginseng, Panax quinquefolius (Araliaceae), across a range of harvest pressures. Ecoscience 16:84-94

Mouquet N, Loreau M (2002) Coexistence in metacommunities: the regional similarity hypothesis. Am Nat 159:420-426

Palmer TM, Young TP, Stanton ML (2002) Burning bridges: priority effects and the persistence of a competitively subordinate acacia-ant in Laikipia, Kenya. Oecologia 133:372-379

Pandit SN, Kolasa J, Cottenie K (2009) Contrasts between habitat generalists and specialists: an empirical extension to the basic metacommunity framework. Ecology 90:2253-2262

Perfecto I, Vandermeer J (2002) Quality of agroecological matrix in a tropical montane landscape: ants in coffee plantations in southern Mexico. Conserv Biol 16:174-182

Pfeiffer M, Tuck HC, Lay TC (2008) Exploring arboreal ant community composition and co-occurrence patterns in plantations of oil palm Elaeis guineensis in Borneo and Peninsular Malaysia. Ecography 31:21-32

Philpott S (2005) Trait-mediated effects of parasitic phorid flies (Diptera: Phoridae) on ant (Hymenoptera: Formicidae) competition and resource access in coffee agroecosystems. Environ Entomol 34:1089-1094

Philpott SM (2006) Ant patchiness: a spatially quantitative test in coffee agroecosystems. Naturwissenschaften 93:386-392

Philpott SM (2010) A canopy dominant ant affects twig-nesting ant assembly in coffee agroecosystems. Oikos (in press)

Philpott SM, Foster PF (2005) Nest-site limitation in coffee agroecosystems: artificial nests promote maintenance of arboreal ant diversity. Ecol Appl 15:1478-1485

Ross JV (2006) Stochastic models for mainland-island metapopulations in static and dynamic landscapes. Bull Math Biol $68: 417-449$

Sale PF (1977) Maintenance of high diversity in coral reef fish communities. Am Nat 111:337-359

Sanders NJ, Gotelli NJ, Heller NE, Gordon DM (2003) Community disassembly by an invasive species. Proc Nat Acad Sci USA 5:2474-2477

Sanders NJ, Crutsinger GM, Dunn RR, Majer JD, Delabie JHC (2007) An ant mosaic revisited: dominant ant species disassemble arboreal ant communities but co-occur randomly. Biotropica 39:422-427

Schluter D (1984) A variance test for detecting species associations, with some example applications. Ecology 65:998-1005 
Selmi S, Boulinier T (2004) Distribution-abundance relationship for passerines breeding in Tunisian oases: test of the sampling hypothesis. Oecologia 139:440-445

Storch D, Sizling AL (2002) Patterns in commoness and rarity in central European birds: reliability of the core-satellite hypothesis within a large scale. Ecography 25:405-416

Ulrich W, Zalewski M (2006) Abundance and co-occurrence patterns of core and satellite species of ground beetles on small lake islands. Oikos 114:338-348
Vandermeer J, Perfecto I, Philpott SM (2008) Clusters of ant colonies and robust criticality in a coffee agroecosystem. Nature 451:457-460

VassarStats (2010) VassarStats: website for statistical computation. http://faculty.vassar.edu/lowry/VassarStats.html

Yu DW, Wilson HB, Pierce NE (2001) An empirical model of species coexistence in a spatially structured environment. Ecology 82:1761-1771 